\title{
Determinants of Women's Participation in the Industrial Economy in Tanzania: A Case of Mwanza Region
}

\author{
Dr. Kaihula P. Bishagazi \\ Saint Augustine University of Tanzania \\ "Corresponding Mail: bkaihula2017@yahoo.com
}

\begin{abstract}
This paper presents findings of an empirical study carried out to identify barriers and enablers of women's participation in the industrial economy in Tanzania, using a case study of Mwanza region, using a cross-sectional design to examine determinants of women participation in the industrial economy in Tanzania. Particularly, a mixed approach involving both qualitative and quantitative data was adopted. Generally, the study reached out to a total of 228 women and 21 Key Informants drawn from 12 sampled wards from two districts of Nyamagana and Sengerema. Data collection involved mainly two approaches: primary data collection through survey, Key Informant Interviews (semistructured), informal interviews, Focus Group Discussions and secondary data through desk review. The study revealed that limited access to financing information, lack of formal education, lack of entrepreneurial knowledge/skills and lack of marketing information are major barriers for women wishing to participate in the industrial economy. Moreover, membership in $\mathrm{CBO}$ and self-confidence are the main enablers of women participation in the industrial economy. Therefore, sensitization programs and establishment of Business Development Services (BDS) at ward levels would help women to access skills and services which will empower them to actively and successfully participate in the industrial economy.
\end{abstract}

Keywords: Industrial Economy, barriers, enablers; Business Development Services (BDS)

\section{Introduction}

Few topics have recently received more comments or been so studied than inequalities between men and women in economic growth participation, the difficulties in promoting it and the possible remedies in overcoming obstacles to achieve it (Rifat \& Ward, 2018). In September, 2015, Tanzania adopted a list of 17 Sustainable Development Goals (SDGs) issued by the United Nations (UN) which aim at accelerating the transition towards sustainable development by 2030 (Bishagazi, 2021). In order to achieve these goals, gender equality and women contribution towards economic activities are perceived to be of high value.

A notable aspect in the implementation of the Five Year Development Plans (FYDPs) in Tanzania is the importance of gender mainstreaming to ensure that women who are marginalized and yet an important economic group in the society are not left behind in achieving an industrial economy (Kerega, 2018). Despite the efforts, women have not been aligned well with the Tanzania's strategic plans. For example, according to Mlote (2018), 53 percent of farmers in Tanzania are women but only 5 percent are involved in value addition/processing to promote an industrial economy.

Without bringing gender equality and integrating women into the economic activities, a great chunk of human capital will remain deprived as a result of which Agenda 2030 will not be achieved holistically. From that end, women economic empowerment is very crucial and thus adequate attention should be given to this matter. According to World Bank (WB) Report (2019), women in Tanzania are found at the bottom rung of poverty, of illiteracy and of landlessness. The reality of women in Tanzania is that they remain a vulnerable marginalized group that is yet to enjoy equality in status and access to services and resources in comparison to their counterparts, men (Idris, 2018).

The economic disparity between men and women has led to a widely differing access to resources and decision making processes, which is partly the 
reason why women's socioeconomic and political status remain low. Katundu, Mhina, Mbeiyererwa and Kumburu, (2013) conclude that, addressing the gap between men and women requires attention to the interplay between households, institutions and markets and how they affect women's status.

The key issues discussed above make the analysis of key determinants of women's participation in the industrial economy crucial in Tanzania. Thus, this paper presents findings of the study carried out to assess factors affecting women's participation in the industrial economy in Tanzania, a case of Sengerema and Nyamagana Districts in Mwanza Region, which was selected mainly for two reasons: First, it ranks the second with higher rate of women than men in Tanzania (National Bureau of Statistics (NBS), 2012). Secondly, the region is endowed with vast of agricultural resources including livestock and fish products which are potential in boosting the industrial economy in Tanzania, particularly through small scale industries. This study intended to guide the government's women economic empowerment strategies by identifying gender-smart policies and solutions to boost participation of women in the industrial economy while at the same time narrowing disparities existing between women and men. In doing so, the study intended to answer the following key questions:

1. What is the level of women's participation in the industrial economy in Mwanza Region?

2. What factors hinder women participation in the industrial economy in Mwanza Region?

3. What factors promote women participation in the industrial economy in Mwanza Region?

\section{Review of Literature}

Early approaches to women in economic development ignored the important role played by women in their communities. In 1970s, a Woman In Development (WID) approach emerged which recognized that more efficient and effective development requires the active participation of both men and women (Boserup, Fei \& Toulmin, 2013). Profounders of this theory include Ester Boserup who advocated for the integration of women into the global economies by improving their status and assisting in total development.

Since mid-1980, there has been a growing consensus that sustainable development requires an understanding of women's roles and responsibilities within the community and their relationship to each other. Later, the development approaches proposed more emphasis on gender relations rather than seeing women's issues in isolation (Boserup, Fei \& Toulmin, 2013). Women, especially those in the lowincome strata, traditionally have contributed to productive activities such as agriculture (mostly small-scale), agro-processing crafts and home industries, trade and commerce. Improving the status of women is no longer seen as just a women's issue but as a goal that requires the active participation of men and women. This has come to be known as the Gender And Development (GAD) approach. The theory highlights changes in modern societies particularly conducive to women's empowerment through industrialization.

Although the industrial sector has historically played a very minimal role in the Tanzania's structural transformation, the desire for the industrial economy is presently re-emphasized via the Tanzania Development Vision, 2025 (Mlote, 2018). The goal of the vision is to transform the economy through industrialization thereby moving the country to middle-income status by 2025 . The main objective of an industrial economy is to achieve the assigned target for the development of industries and provide information about sources of industrial growth (Rifat \& Ward, 2018). The industrial sector of Tanzania is comprised of manufacturing (53\%), processing (43\%) and assembling industries (4\%) (Kerega, 2018). Since agriculture is the mainstay of the Tanzanian economy, the manufacturing industry is centered on the processing of local agricultural goods. The agriculture sector must therefore be transformed to feed the processing industries. This can fully be achieved by involving women in the industrial transformation.

However, women are faced with numerous constraints that limit their ability to participate in the industrial economy. This is revealed by numerous studies which have been conducted to determine the main barriers to their participation in the industrial economy in various contexts. For example, Ayferam (2015) and Wendy, Siong and Chong (2014) found that imbalance between business and household responsibilities and insufficient business skills influenced the performance of micro enterprises owned by women. Yunis, Hashim, and Anderson (2019) stress the need for imparting to women skills necessary to cross-cultural barriers for them to come out openly to undertake the enterprise development. Such skill 
development programs would include enhancement of managerial skills, personal skills, negotiating skills, self-awareness and assertiveness. They further state that the programs need to concentrate on educating men to develop within them an awareness of the influence of their behavior towards women.

Parvin, Rahman and Jia (2012) investigated how difficult it was for women to run their own enterprises in Bangladesh and revealed that while self-achievement was the greatest motivation for women engaged in business, key barriers included insufficient institutional support, lack of market studies, lack of cooperation from the government departments, lack of support from the society, societal restrictions and the oligopolistic approach of investors. To complement these findings, studies of Ahl and Marlow (2019) and Sharma (2017) identified the following as barriers to women enterprise development: family ties, insufficient educational backgrounds, problems in accessing financial resources, high production cost, absence of entrepreneurial aptitude, insufficient managerial capabilities and lack of self-confidence. Several other scholars who have examined various barriers and enablers to women's participation in the industrial economy include Peters and Malik (2016) and Vyas, Mwambo and Heis, (2015).

In Tanzania, credit availability, marketing opportunities, social and regulatory support, access to land and assets, training opportunities and selfconfidence are the most critical factors affecting women's participation in the industrial economy (Idris, 2018). Furthermore, Idris, (2018) stresses that lack of access to credit is the biggest hindrance to women's participation in the industrial economy in Tanzania. He further argues that women's access to financial resources is mostly limited by biased lending practices that emerge when financial institutions consider them smaller, less experienced and therefore less attractive clients, or when these institutions lack knowledge to offer tailor-made products to women's preferences.

Nevertheless, while there are several funds for women entrepreneurs such as the National Entrepreneurship Development Fund of SIDO, the main hindrance is lack of information on their existence and how to access them especially in rural areas. The studies of Arellano-Hernandez (2018) and Al-Kwifi et al (2020) concluded that credit rating, information asymmetry and family influence have a significant effect on access to women enterprise funds. This study therefore investigates on the determinants of women's participation in the industrial economy in Mwanza Region.

\section{Methodology}

This part presents various aspects of the methodology under which this study was conducted.

\section{Research Design}

This study used a cross-sectional design to examine determinants of women participation in the industrial economy in Tanzania. Cross-sectional designs are used by empirical researchers at one point in time to describe a population of interest including age, sex and geographic location (Creswell, 2014). Particularly, a mixed approach involving both qualitative and quantitative methods was adopted in this study. Moreover, the study mainly targeted key stakeholders of women economic disparity.

\section{Population and Sampling}

The study was conducted in Mwanza region located in the Lake Zone in Tanzania. Two districts in the region namely Nyamagana District and Sengerema District were purposively selected because they have great potential for women involvement in industrial enterprise whereby 70 percent of Nyamagana District consists of urban wards while 90 percent of Sengerema District is rural area. This allowed a representation of both rural and urban women.

Nyamagana District is one of the seven districts of Mwanza Region in Tanzania. It is bordered to the north by llemela District, to the east by Magu District, to the south by Misungwi District and to the west by the Mwanza Bay of Lake Victoria. Part of the region's capital, the town of Mwanza, is within Nyamagana District. As of 2012, the population of the Nyamagana District was 363,452 .

On the other hand, Sengerema District is also one of the seven districts in Mwanza Region. The newly created region of Geita borders Sengerema to the west. The headquarters of Sengerema District is located in Sengerema town, $35 \mathrm{~km}$ from Mwanza City. From North to East, the District borders Nyamagana and Ilemela Districts and from the South to the East, the District shares borders with Misungwi District of Mwanza Region. The total geographical surface area is $8,817 \mathrm{Km}^{2}$. Out of this, $3,335 \mathrm{~km}^{2}$ ( 37.8 percent) is covered by the dry land while the remaining $5,482 \mathrm{~km}^{2}$ is covered by the 
water of Lake Victoria. As of 2012, the population of Sengerema District has grown to 663,034 compared to 501,915 in 2002s. Main economic activities in both districts include agricultural production, marketing of agricultural products, livestock keeping and non-farm activities such as carpentry, vending, masonry, etc.
Overall, the study reached out to a total of 228 women and 21 Key Informants such as Local Government Authorities (LGA) officers and ward officers drawn purposively from the sampled wards as shown in Table 1 . These wards were selected using Probability Proportional to Size (PPS). In total, 249 respondents were involved in the study.

Table 1: Population and Sampling

\begin{tabular}{lcc}
\hline Location & Sample of Women & Key Informants \\
\hline Sengerema District & 14 & 2 \\
Sima & 20 & 2 \\
Buzilasoga & 14 & 2 \\
Ibondo & 17 & 1 \\
Misheni & 15 & 2 \\
Kahumulo & 24 & 1 \\
Busisi & 104 & 10 \\
Subtotal & & \\
Nyamagana District & 16 & 3 \\
Mkuyuni & 18 & 3 \\
Nyegezi & 23 & 1 \\
Igogo & 22 & 2 \\
Milongo & 24 & 1 \\
Mabatini & 21 & 1 \\
Buhongwa & 124 & $\mathbf{1 1}$ \\
Subtotal & $\mathbf{2 2 8}$ & $\mathbf{2 1}$ \\
TOTAL & & \\
\hline
\end{tabular}

The sample sizes for both districts were obtained using the Yamane's (1967, p. 886) formula [i.e. $\mathrm{N} /\left(1+\mathrm{N}(\mathrm{e})^{2}\right]$ (at $10 \%$ confidence level); based on a total population of 551,000 women. According to the National Bureau of Statistics (NBS) (2012), there are 185,000 and 366,000 women in Nyamagana and Sengerema Districts respectively. The Yamane's formula was appropriate for this study because the target population was known. This formula is preferred over the Cochran's (1977, p. 39) correction formula [i.e. $n_{0} / 1+\left(n_{0}-1 / N\right)$ for finite population because the Yamane's formula is simpler and flexible whereby it allows calculation of sample size for a different combination of levels of precision, confidence and variability (Ajay \& Micah, 2014). Nevertheless, Sarmah, Hazarika and Chaudhury (2013) provide empirical evidence to show that values calculated through both formulas are in quite good agreement.

\section{Statistical Treatment of Data}

Collection of data in this study was mainly structured around two approaches: primary data collection through survey, Key Informant Interviews (semi-structured), informal interviews and Focus Group Discussions (FGDs) and secondary data through desk review. The desk review encompassed a review of documents provided by respective LGAs and additional information that were obtained through online resources.

Primary data were collected from informationrichest members of the desired population, who were selected purposively in order to generate reliable data. Face interviews and Focus Group Discussions were administered between 28December-2020 and 25-January-2021) in Sengerema and Nyamagana Districts. The Focus Group Discussions and key informant interviews were conducted in Swahili language and they were spontaneously recorded whereby the translation and transcription were done later. This ensured that no important information was lost in the course of the discussions.

Data cleaning and analysis were carried out using Stata Version 12. The analysis sought to establish the levels of determinants and barriers such as education, marital status, age, exposure, capital, market opportunities (covariate effect) and their strength of association (coefficient effect) with women's participation in the industrial economy. The factors that were tested are known in the literature to influence women in the participation in the industrial economy (e.g. see: Sharma, 2017; 
Vyas, Mbwambo, \& Heise, 2015; Peters and Malik, 2016; and Losindilo, Mussa \& Akarro, 2010). Logistic regression analysis was carried out to estimate the strength of association (coefficient effect) of participation in the industrial economy determinants among women. Qualitative data analysis was mainly done through thematic analysis whereby the researcher mainstreamed all different themes and sub-themes that emerged and put the analysis in the chronological order. Apart from that, triangulation was used to compare information gathered from different sources such as literature, interviews, Focus Group Discussions (FGDs), documents and observations. According to Bishagazi (2016), triangulation enables the researcher to address different angles of the issue at hand and thus increasing the chance of the research achieving high degree of reliability. This further helps to overcome single method limitations (Bryman \& Bell, 2015).

\section{Validity and Reliability}

Haradhan (2017) defines reliability as the ability of a measure to remain constant despite uncontrolled testing conditions. Cronbach alpha is the most commonly approach used to determine the internal consistency of an instrument (Heale, 2015). Haradhan (2017) suggests that for the social sciences, the acceptable range of Cronbach's alpha value estimates range from 0.7 to 0.8 . The researcher tested the internal consistency of the questionnaire tool that was used for data collection. Cronbach's alpha was calculated and was found to be appropriate at 0.74 which indicates that the measurements employed in this study are reliable and consistent.

To ensure content validity, Aburaya (2012) advises that at the initial stages of the questionnaire development, experts in the subject matter who can comment on both the suitability and structure of the questionnaire should assess it. The questionnaire was therefore given to two experts, one being an expert in research methodology and the other being a gender expert. They evaluated the instrument to ensure that it accurately represented the concepts under study.

\section{Ethical Considerations}

During data collection, the researcher kept data collection procedures as brief and convenient as possible to minimize disruptions in respondents' work processes. To ensure potential participants made informed decisions, the researcher asked them to sign a consent form, informed them about the purpose of the assignment and final outcome and explained the process and duration of the process. The researcher also ensured respondents' confidentiality and allowed them to retain from answering questions posed in case they felt uncomfortable to respond. Key informants were interviewed face to face without presence of other individuals and their identities were not revealed. As for the Focus Group Discussion, the groupings were applied to encourage open discussions around the questions by avoiding presence of their superiors. The Focus Group Discussions were held separately for each targeted group. Furthermore, permission for data collection was obtained from the Regional Administrative Secretary (RAS).

\section{Results and Discussion}

The analysis and presentation of results was guided by three research questions as follows:

Research Question 1: What is the Level of Women's Participation in the Industrial Economy in Mwanza Region?

Defined as the number of women with a small scale industry/involved in processing goods given as percentage of the working age population, data analysis from the survey made shows that the level of participation of women in the industrial economy in Mwanza region is 5 percent. These findings are similar to the conclusion made by Mlote (2018) who concluded that the level of women's participation in the industrial economy in Tanzania is 5 percent.

Further analysis shows that the participation rate varies by education level. All sampled women owning successful processing units have at least ordinary level secondary education. These processing units include wine making, oil processing and flour making. Unfortunately, processing units of uneducated women were not sustained and most of them are not functioning well. Parvin, Rahman and Jia (2012) provide evidence of how challenging it is for uneducated women to sustain a processing unit.

Furthermore, survey data show that participation in the industrial economy among women is driven by poverty and the need for income rather than from entrepreneurial aspirations, concentrated efforts to secure business opportunities or knowledge of their role in the industrial economy. Women in Mwanza region engage in enterprise development due to the need to supplement family income, especially when their husbands are deceased, become irresponsible, unemployed or do not earn enough money to

173 East African Journal of Education and Social Sciences (EAJESS) 2(2)169-178 
sustain the family. These findings are in contrast to Rifat and Ward (2018) who found that most women are motivated to establish their own small scale industries due to lack of other economic opportunities in a context of high unemployment rate.

Despite high unemployment rates and low income earned from agricultural products by women in Mwanza Region, most of them wish to continue with selling agricultural products but at a large scale. Only a small fraction of women reported serious aspirations to be involved in the industrialized nonagriculture activities. Participation in the industrial economy by women through small scale industries in Mwanza Region is not perceived as an attractive career opportunity, especially among young women. Therefore, women under investigation were not aware and did not understand their role as potential participants in the industrial economy.

Research Question 2: What factors hinder women's participation in the Industrial Economy in Mwanza Region?

This research question sought to establish factors that hinder women's participation in the Industrial Economy as revealed by table 2 which indicates the participation in the Industrial Economy Status Estimates (Treatment Equations) of the endogenous treatment effects model with an ordered outcome.

Table 2: Factors Hinder Women's Participation in the Industrial Economy

\begin{tabular}{|c|c|}
\hline Selected Factors & Participation \\
\hline \multirow[t]{2}{*}{ Level of formal education } & $-0.9213^{*}$ \\
\hline & $(0.0000)$ \\
\hline \multirow[t]{2}{*}{ Place of residence } & -0.3932 \\
\hline & $(0.3051)$ \\
\hline \multirow[t]{2}{*}{ Age } & 0.3995 \\
\hline & $(0.3001)$ \\
\hline \multirow[t]{2}{*}{ Religion } & 0.0513 \\
\hline & $(0.3028)$ \\
\hline \multirow[t]{2}{*}{ Marital status } & -0.1248 \\
\hline & $(0.2597)$ \\
\hline \multirow[t]{2}{*}{ Technical Skills } & $-0.6876^{*}$ \\
\hline & $(0.0000)$ \\
\hline \multirow[t]{2}{*}{ Respondent's willingness to participate in the industrial economy } & 0.4292 \\
\hline & $(0.2840)$ \\
\hline \multirow[t]{2}{*}{ Family/domestic responsibility } & $-0.0882 *$ \\
\hline & $(0.0130)$ \\
\hline \multirow[t]{2}{*}{ Nature of economic activity } & -0.2363 \\
\hline & $(0.1735)$ \\
\hline \multirow[t]{2}{*}{ Credit/Capital } & $-0.5625^{*}$ \\
\hline & $(0.0000)$ \\
\hline \multirow[t]{2}{*}{ Access to Market Information } & $-0.3468 *$ \\
\hline & $(0.0210)$ \\
\hline \multirow[t]{2}{*}{$\mu_{1}$} & -0.8300 \\
\hline & $(0.2688)$ \\
\hline \multirow[t]{2}{*}{$\mu_{2}$} & 0.5294 \\
\hline & $(0.2731)$ \\
\hline
\end{tabular}

Note:

Estimated are weighted using the survey weights

Figures in Parentheses are Standard Errors

*Significant at 5\% Confidence Level

Results in table 2 provide an insight into the main barriers of women's participation in the industrial economy. Out of 11 factors, only 5 have turned to have a significant effect on women's participation in an industrial economy. These are level of education (i.e. $\beta=-0.9213, p=0.0000$ ), lack of technical skills (i.e. $\beta=-0.6876, p=0.0000$ ), family responsibilities (i.e. $\beta=-0.0882, p=0.0130$ ), lack of credit information (i.e. $\beta=-0.5625, p=0.0000$ ) and lack of market information (i.e. $\beta=-0.3468, p=0.0210$ ). Of all, lack of formal education and lack of technical skills are the most important barriers of women's participation in the industrial economy. From table 2, women with no formal education are 92 percent 
less likely to be engaged in the industrial economy. Moreover, women with no technical skills are 64 percent less likely to start a small scale industry. Women with no access to credit information are 56 percent less likely to be involved in the industrial economy.

These results have implications for women's participation in the industrial economy where a certain level of formal education/training is needed. Thus, illiteracy and or lower educational attainment are barriers for women participation in the industrial economy.

Most women do not have financial independence and enough savings to start up an enterprise. Therefore, if a woman wants to start a business, she needs to get a loan and may face difficulty due to lack of collateral and guarantee. Because most women earnings rely on farming and animal husbandry, during the seasons with harsh weather and lack of rainfall, they may not produce enough and as a result face financial difficulties and default on their loans, and this may pose a big obstacle to developing an enterprise.

Moreover, 'family responsibility' coefficient as expected was negative, reflecting that the larger the family size, the less likely women choose to engage the industrial economy. Women's primary role is traditionally perceived as and expected to be in the house, as housewives or mothers, and men are supposed to be involved in outside activities including income generation. Pregnancy, child bearing and rearing are purely considered female functions. The nurturing skills related to child rearing require more time and involvement in household activities. Consequently, this limits women's responsibilities and involvement in activities outside of the households. Role conflict or balancing time between these different roles is found to be a problem for many women aspiring to be involved in the industrial economy in Tanzania.

A study of Ahl and Marlow (2019) found that women basically lack access to credit probably because of their low level of savings as well as the lack of the necessary collateral needed for the acquisition and repayment required for a loan. Furthermore, the bureaucracy involved in acquiring a loan is too complex and daunting for most women especially those with little or no educational background. Furthermore, the authors add that some banks and other financial institutions consider women as risky customers because they either lack collateral which they seek before granting a loan or that the businesses that women are involved in are not stable and structured enough to fit into their clientele. Thus most women are denied access to formal credit and are therefore not able to improve upon their economic activities and to move away from subsistence-based to profit-based business activities.

Table 3: Factors Promoting Women's Participation in the Industrial Economy

\begin{tabular}{|c|c|}
\hline Selected Factors & Participation \\
\hline \multirow[t]{2}{*}{ Membership in CBO } & $0.3822^{*}$ \\
\hline & ( 0.0013$)$ \\
\hline \multirow[t]{2}{*}{ Self confidence } & $0.5678^{*}$ \\
\hline & ( 0.0001$)$ \\
\hline \multirow[t]{2}{*}{ Type of occupation } & 0.0183 \\
\hline & $(0.0453)$ \\
\hline \multirow[t]{2}{*}{ Level of exposure } & 0.0235 \\
\hline & (0.0255) \\
\hline \multirow[t]{2}{*}{ Social Class } & 0.0461 \\
\hline & $(0.1004)$ \\
\hline \multirow[t]{2}{*}{ Awareness } & 0.0863 \\
\hline & $(0.0626)$ \\
\hline \multirow[t]{2}{*}{$\mu_{1}$} & 0.7387 \\
\hline & $(0.2545)$ \\
\hline \multirow[t]{2}{*}{$\mu_{2}$} & 1.2442 \\
\hline & $(0.2335)$ \\
\hline
\end{tabular}

Note:

1. Estimated are weighted using the survey weights

2. Figures in Parentheses are Standard Errors

3. *Significant at $5 \%$ Confidence Level 
Similarly, Yunis, Hashim, and Anderson (2019) found that women also lack business and marketing skills that may allow them to put together viable business proposals. Women have less access to formal channels that provide comprehensive skills training because they are mostly unaware of the existence of such programs and even when they are aware, time constraints may limit their access to such programs.

Research Question 3: What Factors Promote Women's Participation in the Industrial Economy in Mwanza Region?

This research question sought to determine factors promoting women's participation in the Industrial Economy as revealed in table 3 (p. 175) which indicates participation in the Industrial Economy Status Estimates (treatment equations) of the endogenous treatment effects model with an ordered outcome.

The table presents logistic regression results relating to key enablers of women's participation in the industrial economy whereby only membership in the $\mathrm{CBO}$ (i.e. $B=0.3822, p=0.0013$ ) and selfconfidence (i.e. $B=0.5678, p=0.0001$ ) are statistically significant. This means that a woman who is registered in the $\mathrm{CBO}$ is 38 percent more likely to be engaged in the industrial economy. Similarly, a woman who is confident is 57 percent more likely to be involved in the industrial economy.

One of the approaches used by women to have easier access to enterprise development is membership in $\mathrm{CBO}$. This is viewed as a way to share risks whereby women get an opportunity to develop entrepreneurial knowledge and new business ideas. It is also important to note that 78 percent of sampled women are affiliated with a CBO. Affiliations in associations as a form of networking increase member's awareness, women's access to experience based information on how to start and run a businesses and therefore plays an important role in women enterprise development success. Most importantly, membership in a CBO is one of the important requirements to get access to finance and trainings. In addition, one of the most cited factors that promote women's participation in the industrial economy is high level of selfconfidence as demonstrated in the sample survey of the personal characteristics self-rating questions administered during the study.
Similar conclusions were made by Peters and Malik (2016) and Vyas, Mwambo and Heise (2015). For example, the study of Peters and Malik (2016) showed that self-confidence is a significant factor in boosting women's participation in an industrial economy. Kerega (2018) argued that when women have more access to technical trainings, it helps to boost their confidence that with the right knowledge, education and capital, they can successfully participate in the industrial economy. Ayferam (2015) further showed that women with a high level of personal initiative tend to overcome obstacles to the business and obstacles of the self to effectively work towards business success.

\section{Conclusions and Recommendations}

Generally, women lack confidence, self-esteem and political will to be involved in enterprise development; which is mainly due to traditional gender roles. Therefore, a mass campaign for sensitization and change of mind set are required to enable women to realize their role in the industrial economy and thus increasing their participation in the industrial economy. This is the only way which will ensure enterprise development and sustainability, thus opening avenues for more involvement of women in the industrial economy.

Women have a higher potential to be engaged in the industrial economy in Tanzania due to availability of agricultural resources which can be processed/ semi processed for value addition in small scale industries. However, existing infrastructure is still inadequate to meet special needs of these women. The domestic work burden for them is too great. Therefore, there is a serious need to introduce practical, proactive and innovative measures which are tailor made to women for sustainable enterprise development.

Besides limited access to finance and a lack of technical skills, lack of market and marketing information, and family responsibility are identified as major barriers for women wishing to participate in the industrial economy. Thus, to unleash the potential of women in both rural and urban areas, an enabling business environment in which interventions systematically address the numerous barriers that women face are needed to be established and expanded. Effective enterprise development requires the needs of different sets of women (e.g.: rural, urban, small-scale, skilled, unskilled, crippled etc.) to be taken into account. Therefore, credit facilities should be tailor-made to 
women needs. Furthermore, close and frequent monitoring of credit facilities given to women is very crucial. There is also a need for the use of social media and online business to boost access to market.

Finally, the challenges identified give credence to women's preference to only be engaged in agricultural activities and hesitate to be involved in the industrial economy. This goes to show that, their existence are potentially productive human capital for the industrial economy in the form of women, which needs harnessing. To tap this potential will require adequate investment in the form of education and skill training and to provide the requisite guidance, the capital needed and appropriate markets to engage more women in the industrial economy.

\section{Acknowledgement:}

The research is financed by Small Industries Development Organization (SIDO)

\section{Reference}

Aburaya, R.K. (2012). The Relationship between corporate governance and environmental disclosure: UK Evidence, PhD Thesis, Durham University, United Kingdom.

Ahl, H. and Marlow, S. (2019). Exploring the false promise of entrepreneurship through a postfeminist critique of the enterprise policy discourse in Sweden and the UK. Human Relations 1-28.

Ajay, S,. and Micah, M. (2014). Sampling techniques and determinants of sample size in applied statistics research: An overview, International Journal of Economics, Commerce and Management, 11 (11), 1-22.

Al-Kwifi, Osama S., Tran T. Khoa, Viput Ongsaku, and Zafar U. Ahmed. (2020). Determinants of female entrepreneurship success across Saudi Arabia. Journal of Transnational Management 25: 3-29.

Arellano-Hernandez M.H (2018). Women's Economic Empowerment: Factors Affecting Women's Participation In MicroEnterprises. International Journal of Advanced Research and Publications 2(12), 85-90.

Ayferam, G. (2015). "Assessment of the roles and constraints of women in economic development of Ethiopia: the case of Ambo town since 1991. Journal of Political Sciences \& Public Affairs: 1-11.

Bishagazi, K. (2016). Firm-Level Factors and Voluntary Corporate Disclosure In Tanzania: A Comparative Study of the Mining and Manufacturing Industries. Phd Thesis, Catholic University of Eastern Africa (CUEA), Kenya.

Bishagazi, K. (2021). Localizing Sustainable Development Goals (SDGs) in Tanzania: Redefining Responsibilities (Issue Brief No. 2). Tampere Peace Research Institute (TAPRI).https://pilot4dialogue.com/publicati on/study1_overview/policy_brief_2/

Boserup, E., Fei, S.T. and Toulmin, C. (2013). Woman's Role in Economic Development, New York:NY, Routledge publishers.

Bryman, A., and Bell, E. (2015). 4th edition. Business research methods, Oxford: Oxford University Press.

Cochran, W. G. (1977). Sampling Techniques. (3 ${ }^{\text {rd }}$ Edition). John Wiley \& Sons. New York.

Creswell, J. (2014). Research Design: qualitative, quantitative and mixed method approaches. SAGE Publications, ( $3^{\text {rd }}$ Edition), Los Angeles.

Gryshova, I.; Shabatura, T.; Girdzijauskas, S.; Streimikiene, D.; Ciegis, R.; and Griesiene, I. (2019). The Paradox of Value and Economic Bubbles: New Insights for Sustainable Economic development. Sustainability, 11, 6888.

Haradhan, M. (2017). Two Criteria for Good Measurements in Research: Validity and Reliability. Annals of Spiru Haret University, 17(3), 58-82.

Heale, R. \& Twycross, A. (2015). Validity and reliability in quantitative studies Evid Based Nurs July 2015 | volume 18 | number 3 retrieved from http://ebn.bmj.com/

Idris, I, (2018), 'Barriers to women's Economic Inclusion In Tanzania'. K4D Helpdesk Report. Brighton, UK: Institute of Development Studies.

Katarina, Helene Ahl, Karin Berglund, and Malin. Tillmar. (2017). In the name of women? Feminist readings of policies for women's entrepreneurship in Scandinavia. 
Scandinavian Journal of Management 33: 50-63. Pham, Tho, and Oleksandr Talavera. 2018.

Katundu, M A, Mhina, M, L, Mbeiyererwa, A, G. \& Kumburu, N, P, (2013) Socio-economic factors limiting smallholder groundnut production in Tabora region', Draft Report for REPOA"s 18thAnnual Research Workshop, Dar es Salaam, Tanzania.

Kerega, P. A (2018). Understanding the Industrial Economy and Workers' Rights in Tanzania: Prospects and Challenges Under a New Industrial Strategy. Journal of Human Resources Management and Labor Studies, $6(1), 1-12$

Losindilo E., Mussa A., Akarro, R (2010). Some factors that Hinder Women Participation in Social, Political and Economic Activities. Arts and social sciences journal, vol. ASSJ 4.

Mlote, S. (2018). Integrating Food and Nutrition Security into Economic Transformation and Industrialization Agenda. Paper presented in the $4^{\text {th }}$ Annual Agricultural Policy Conference, Dar es salaam, Tanzania.

National Bureau of Statistics (NBS) [Tanzania]. 2012. Tanzania National Household Survey Report (NHS).

Parvin, Lovely, M. Wakilur Rahman, and Jinrong Jia. (2012). Determinates of women microentrepreneurship development: An empirical investigation in rural Bangladesh. International Journal of Economics and Finance 4, 254-60.

Peters E. and Malik A. (2016) Women's Economic Empowerment: A Review Of Evidence On Enablers And Barriers. Working Paper.
Rifat, and Kathryn B. Ward. (2018). Globalization and gender equality: A critical analysis of women's empowerment in the global economy. Advances in Gender Research 13, 141-73.

Sarmah, H., Hazarika, B., and Chaudhury, G. (2013). An investigation of the effect of bias on determination of sample size on the basis of data related to the students of schools of Guwahati, International Journal of Applied Mathematics and Statistical Sciences, 2 91), 33-48.

Sharma G, Bansal H (2017). Determinants and Indicators of Women Empowerment: A Walk-Through Psychological Patterns and Behavioral Implications. Research Journal of Business Management 11(1), 15-27

The World Bank Annual Report (2019). The World Bank.

Wendy M. Y., and Siong C. Chong. (2014). Towards strengthening the development of women entrepreneurship in Malaysia. Gender in Management 29, 432-53.

Vyas, Seema; Jessie Mbwambo; and Lori Heise. (2015). "Women's Paid Work and Intimate Partner Violence: Insights from Tanzania." Feminist Economics 21 (1), 35-58.

Yamane, T. (1967). Statistics: An introductory analysis. $2^{\text {nd }}$ edition. Harper and Row, New York.

Yunis, Mohammad S., Hina Hashim, and Alistair R. Anderson. (2019). Enablers and constraints of female entrepreneurship in Khyber Pukhtunkhawa, Pakistan: Institutional and feminist perspectives. Sustainability 11: 27. 